\title{
The scientific labour market in Europe
}

Josephine Anne Stein and Nicole Kurtz

The United Kingdom, almost alone among European countries, does not have internationalization as an integral part of its education and training policy.

LABOUR market conditions for scientists and engineers in the United Kingdom have been dominated in the past few years by a combination of growth in student numbers and the economic recession. The United Kingdom was the only member state of the European Communities (now the European Union) in which government research and development (R\&D) expenditure declined in the second half of the 1980s. Industrial R\&D expenditure declined in 1989 and has not grown appreciably since. As trends in hiring research personnel tend to lag behind $\mathrm{R} \& \mathrm{D}$ expenditure, this is consistent with observations that British industry has reduced its recruitment of scientists and engineers. Although there is anecdotal evidence that British employers are tending to hire UK nationals preferentially, unemployment among recent UK graduates appears to be causing more students to stay in higher education, and deterring others from entering science and technology in the first place.

The completion of the Single Market and political steps towards European union have brought the UK system into abrupt contact with the rest of the European Union (EU). International education and training for scientists and engineers has become important to companies seeking to Europeanize their business operations, to higher education institutions preparing students for employment on the mainland of Europe, to public authorities seeking to improve regional and national positions in Europe, and, of course, to scientists and engineers themselves. The United Kingdom supports some schemes for international education and training, but it is the EU that provides the most extensive opportunities for UK scientists and engineers.

EU research fellowships and educational exchange schemes such as Comett and Erasmus have had a substantial impact in the United Kingdom. Nearly a quarter of UK Erasmus students go abroad to study mathematics, the natural sciences and engineering. Both incoming and outgoing students are very enthusiastic about the value of these exchanges, as are most academic staff.

The United Kingdom sent the most students abroad in Comett II, and in receiving students, organizing courses and training projects, was second only to France. Two-thirds of all proposals submitted in 1992 involved a UK partner.
The EU's Human Capital and Mobility (HCM) scheme supports roughly threequarters of research fellowship exchanges in the Framework Programme. Britain is the most popular destination for HCM individual fellows, with more than a third of the host laboratories in the EU. It also has the greatest number of host laboratories for institutional fellowships and is the member state with the greatest number of participations in networks.

Interestingly, the Office of Science and Technology's recently published Forward Look does not refer to the international dimensions of education (other than to acknowledge the research income that universities receive from the EU). Nor does the Forward Look address the European dimension of the labour market, or the needs of UK industry for an internationally educated and trained scientific and technological workforce.

UK policy is in striking contrast to other European countries in which internationalization of the science and engineering community is integral to national policy. For example, the Dutch government is committed to internationalizing its entire higher educational system, even for Dutch students enrolled in Dutch universities who will find employment in the Netherlands. France also has an explicit policy to internationalize both its student population and the scientific workforce. Germany and Belgium are implementing educational exchange programmes, primarily on a regional basis. In Ireland and Portugal, EU schemes are integrated into national policies for education and employment of scientists and engineers. Only in Italy is there a comparable focus on reform of the national educational system in response to national demand by employers.

Despite the predominance of national educational systems and labour market conditions in the EU countries, a Europeanized labour market is gradually emerging as a cumulative result of EU and other European programmes for international education and training. International recruitment and employment are no longer unusual. Certain policy issues arise as a consequence.

There are some practical barriers to European educational mobility. Comett, Erasmus and EU research fellowships have suffered poor take-up because of the length of time required to set up exchanges, and mismatches between academic calendars. There are only five weeks of the year in which universities in all parts of the EU are in teaching session. Information is fragmented and relatively inaccessible, as it arises from so many different quarters and is often aimed at specific groups of people within individual countries or specialized professional occupations.

As exchanges and internationalized curricula develop across Europe, there is no systematic assessment of courses or qualifications. The European Course Transfer System is embryonic and completely voluntary; assessment of equivalences of degrees and diplomas is done on a case-by-case basis. The challenge of developing a comprehensive approach is complicated by the educational reforms under way in a number of European countries. Although a number of so-called 'Euro' degrees are offered by universities or academic/industrial consortia, external recognition is virtually nonexistent.

The Single Market guarantees equal access to education for all European Union nationals and the free movement of labour. Any structural differences in either the educational systems or the national labour markets could therefore lead to imbalances in mobility. This raises the policy question of where the responsibility lies for underwriting the costs of education, which are substantial for science and engineering courses. Should it fall to the home country, the host country or the employer, who may be in yet another country? Should the European Union, given greater responsibilities for education and training under the Maastricht Treaty, assume greater financial responsibility as well?

Although it is not yet clear how far Europeanization of the labour market will progress, there is a clear need for further policy development at both national and European level.

Josephine Anne Stein is at the Programme of Policy Research in Engineering Science \& Technology, University of Manchester, London Office, 8 John Adam Street, London WC2N 6EZ, UK, and Nicole Kurtz is at the Centre National de la Recherche Scientifique, CNRS Office, Ambassade de France, 6 Cromwell Place, London SW7 2JN.

The authors would like to acknowledge the support of the Economic and Social Research Council (UK) the Centre National de la Recherche Scientifique (France) and the Science Policy Support Group (UK) 